\title{
Modeling, simulation and forecasting of wind power plants using agent-based approach
}

\author{
Imran Mahmood a, b, *, Mahe Mobeen ${ }^{\text {b }}$, Anis Ur Rahman ${ }^{\mathrm{b}}$, Shahzad Younis ${ }^{\mathrm{b}}$, \\ Asad Waqar Malik ${ }^{b}$, Muhammad Moazam Fraz ${ }^{\text {b }}$, Kafait Ullah ${ }^{\mathrm{C}}$ \\ a Department of Computer Science, College of Engineering Design and Physical Sciences, Brunel University, Kingston Lane Uxbridge London, London, UB8 \\ $3 P H, U K$ \\ b School of Electrical Engineering and Computer Science (SEECS), National University of Sciences and Technology (NUST), Islamabad, Pakistan \\ ${ }^{\mathrm{c}}$ Department of Energy System Engineering, U.S.-Pakistan Center for Advanced Studies in Energy, National University of Sciences and Technology (NUST), \\ Islamabad, Pakistan
}

\section{A R T I C L E I N F O}

\section{Article history:}

Received 5 May 2020

Received in revised form

12 August 2020

Accepted 9 September 2020

Available online 15 September 2020

Handling editor. Cecilia Maria Villas Bôas de Almeida

\section{Keywords:}

Wind power plants

Modeling and simulation

Agent-based approach

Forecasting

Time series analysis

\begin{abstract}
A B S T R A C T
National economy and growth rely heavily on electricity but rapid urbanization, expeditious industrialization and increased domestic use due to population growth are among the reasons for the severe energy crisis in developing countries. The extended demand-supply gaps, depleting reservoirs of fossil fuel, and the environmental hazards altogether ignite the need for wider adoption of renewable energy resources for electricity generation. A functional assessment of the engineering design for this transition is a prerequisite before proceeding to on-ground implementation due to its high impact on system sustainability. To this end, we propose an agent-based modeling and simulation framework for the rapid prototyping of wind power plants. The proposed approach abstracts active components of wind power plants using agents and implements their dynamic behavior through agent interactions. The proposed model helps in composing different model components, design valuation, and forecasting energy generation in a cost-effective and productive manner. The proposed model is demonstrated by conceptualizing the design of the Foundation Wind Energy plant, located at Sindh, Pakistan, and the development of its agent-based model. The obtained short-term and long-term electricity generation profiles are validated with the actual data. We further compared the forecasts with the time series analysis performed on the actual data, using five different time-series forecasting models. The proposed simulation model and time series analysis model fit well on the actual data with a root mean square deviation of approximately $9 \mathrm{MW}$. The proposed framework will assist the policymakers in estimating the extent of electrical energy produced at given conditions using the wind potential available at the corridors of any country. It will further aid in the realistic analysis of the future dynamics of electricity demand and supply, hence help in effective energy planning.
\end{abstract}

(C) 2020 Elsevier Ltd. All rights reserved.

\section{Introduction}

In developing countries, the increase in energy demand due to rapid growth in population, exponential rise in urbanization, infrastructure modernization and industrialization have led to a severe energy crisis. This results in frequent load shedding and

\footnotetext{
* Corresponding author. Department of Computer Science, College of Engineering Design and Physical Sciences, Brunel University, Kingston Lane Uxbridge London, London, UB8 3PH, UK.

E-mail addresses: imran.mahmood@brunel.ac.uk, imran.mahmood@seecs.edu. pk (I. Mahmood).
}

unscheduled power outages, which cause disruption in economic and domestic activities (Ebinger, 2011; Valasai et al., 2017). For instance, as per World Bank report, the power sector inefficiencies cost Pakistan $\$ 18$ billion, which is approximately 6\% of its GDP (Zhang, 2018). The main source of electricity generation in Pakistan is the imported fossil fuel. Besides imposing a heavy import bill on the country's economy, it is not an environmentally friendly source of electricity production due to toxic emissions (Castillo et al., 1976). The extended demand-supply gaps, heavy burden on the economy, world-wide depletion of fossil fuel reservoirs, and the environmental hazards altogether ignite the need to change the electricity generation methods, and to move forward towards greener, cost 
effective and environment friendly renewable energy resources.

Renewable energy can effectively be produced in Pakistan as ample solar irradiance and suitable wind corridors are available in the country. This will help in addressing the energy shortfall and assist in sustainable human development and persistent economic growth. It is prerequisite to understand the dynamics of the existing system for strategic planning and policy making to integrate the renewable energy generation in the system (Shahid et al., 2020). The dynamics of energy generation and consumption along with its associated factors, is needed to be modeled and analyzed at the country scale, which assists in strategic planning to meet longterm targets through sustainable, efficient and affordable renewable mix. According to economic assessment of energy generating systems, it has been revealed that the cost associated with power generation plants includes cost of development, capital cost, operations, initial investment and fuel cost (Chu and Majumdar, 2012). It is therefore important to know about the plant's productivity before installing it (Guo et al., 2020). Hence, a prerequisite is to build a greater confidence in the engineering design before implementation, through the use of modeling and simulation (M\&S) techniques (Fujimoto et al., 2017; Mahmood et al., 2019, 2020a).

\subsection{Energy system modeling}

Energy system modeling serves as basis for making strategic decisions where the dynamics of the energy system are evaluated by using empirical data sets and through the use of simulation models of energy generation, transmission and consumption processes. It is desirable to deploy a dynamic electricity model to investigate the behavioral dynamics of the energy generation of a power plant under varying conditions, at varied time scales, and with complex heterogeneous behavior of the underlying key components of the power plant. All of that cannot be easily be described by simply aggregating the individual entities. The need for such a system is magnified when considering renewable energy resources with complex dynamics and spatio-temporal variations.

Modeling, Simulation and forecasting of wind energy generation potential in Pakistan will help energy planners, energy suppliers and strategy makers to take into account electrical energy that can be produced by wind's mechanical energy. This will help to bring a decrease in demand and supply gap. Therefore, we propose a component-based approach to model wind turbine system and simulate its generation using external parameters such as wind speed. The model is based on component-based approach (Mahmood et al., 2019) that allows the use of different combinations to evaluate an engineering design. It takes into account working of different components to forecast energy generation at different wind speeds at different instance of time. This forecast of long term and short-term energy generation profile can be used in a productive manner to aid in realistic analysis of the future dynamics of electricity demand and supply.

\subsection{Agent-based modeling (ABM)}

$\mathrm{M} \& \mathrm{~S}$ allows us to replicate a real-world system for risk-free dynamic experiments, which are otherwise impossible, dangerous or costly as well as time-consuming. ABM is a paradigm meant for abstracting the structure, behavior and the interactions of the entities of a complex real system, in the form of small, reproducible units known as agents (Mahmood et al., 2020a). The collection of these modeled agents is viewed as a composed model to assess their emergent effect on the system as a whole (Taylor, 2014). They interact with one another in an environment where they start representing a complex system behavior. ABM can possess different qualities and characteristics allowing the appearance of distributed intelligence. ABM has been applied to numerous fields successfully and is now paving its path towards power grids and electricity market. It can be combined with different other approaches as well such as system dynamics and discrete event, if needed to the best project a model (Kremers et al., 2011). Applications of ABM provide abstraction of real systems, at a microscopic level to model and explore complex behavior over time. Microscopic models help in simulating real-world problems with higher resolution, as these consider granular details. Our experience show that neglecting these details can produce minor deviations from the actual results if not considered (Alvi et al., 2018). An ABM is the composition of individual agents, populated in a discrete or continuous environment. Each agent individually assesses its situation, makes decision on basis of certain set of rules and changes its states based on stimuli generated from other agents or from the environment. The emergent behavior resulted from the individual behaviors and interactions between these agents affects the aggregated level of the combined system. ABM technique is used by many researchers as suitable approach for complex sociotechnical problems; having dynamic temporal and spatial scales; and the entities of the real system being at different resolutions; particularly to study the electricity markets (Ringler et al., 2016).

Despite the customary usefulness of the conventional modeling approaches, they often have limitations because they treat the system components as homogeneous entities using a single monolithic model. In addition, they fail to express properties of complex systems, such as hierarchical forms, collective behavior, evolution and adaptation, interconnected networks, due to their top down nature and central-logic (Mahmood et al., 2020b). Our main motivation in using ABM approach is its effectiveness in studying complex adaptive systems through a systematic abstraction of the system using a 'bottom-up approach'. Generally, ABM approach solves real-world problems, effectively when the knowledge of the real-world system is available but the data is missing or sparse. It enables experimentation on a valid virtual environment representing the real-system. Unlike physical modeling, agent-based modeling is based on rule-sets, algorithms and equations. They are often used to conduct experiments on a real system that is impossible or impractical, often because of cost or time. Across industries and disciplines, it provides valuable solutions by giving clear insights into complex systems.

In this paper, we present an application of the ABM paradigm and propose a hierarchical agent-based modeling and simulation framework for the rapid prototyping of wind power plants which help compose different model components, evaluate the design and forecast energy generation in a cost effective and productive manner. Our approach abstracts active components of wind power plants using agents and implement their dynamic behavior through agent interactions. To demonstrate our approach, we conceptualized the design of the Foundation Wind Energy, located at Gharo, District Thatta, Sindh, Pakistan and develop its agent-based model. Our short term and long term generation profiles are validated with the actual data, for the proof of concept. We further compared our forecasts with the time series analysis performed on the actual data, using different time-series forecasting models. There are several advantages associated with the unique properties of our proposed framework: It is built in the form of a hierarchy to conceptualize the complexity of the actual wind power plant system, which is composed of interrelated subsystems. The architecture of a complex system is a function of its components and their hierarchic relationships. The main advantage of hierarchical modeling is the reduction of complexity through the logical decomposition. We conceptualize the wind power plant as a hierarchic structure, which is composed of different entities, as 
discussed in Section 3.

Our proposed framework will help decision makers estimating the extent of Electrical Energy produced at given conditions using available wind potential available at the wind corridors of any country, and will aid in realistic analysis of the future dynamics of electricity demand and supply.

Key contributions of this paper include:

(a) Proposed an agent-based modeling and simulation framework for the rapid prototyping of wind power plants.

(b) Proposed a component-based framework to allow composing different model components, design valuation, and forecasting energy generation.

(c) Modeled active components of wind power plants along with dynamic behavior implemented through agent interactions.

(d) Demonstrated the approach by conceptualizing the design of the Foundation Wind Energy plant, located in Sindh, Pakistan.

(e) Validated the obtained short term and long term electricity generation profiles with actual data with a root mean square deviation of approximately 7 MW.

(f) Compared simulated forecasts with time series analysis performed on the actual data using five different time-series forecasting models.

The rest of the paper is organized as follows: Section 2 reviews the literature associated with this paper. Section 3 describes our proposed framework. Section 4 covers the case study conducted on a real world power plant to demonstrate the proof of concept. Section 5 illustrates the simulation procedure, results and model validation and Section 6 sketches the conclusions and future work.

\section{Literature review}

In this section we present the literature review of this research, divided in the following categories:

\subsection{Wind turbine systems}

Wind turbine design involves complex engineering as it particularly deals with the conceptual design and assembling of various mechanical, electrical and electronic components to extract maximum energy out of wind resources. The main concern is to produce cheaper electricity, as compared to other electricity generation methods. Therefore, it is essential to design a cost-effective wind turbine, using Modeling and Simulation tools. Further, different techniques have been proposed in the literature, to achieve an optimal design through modeling techniques. Manwell et al. (2010) discuss different architectures of the wind turbine system, depending upon the application for commercial or domestic purposes. Similarly, Mohit et al. (Singh and Santoso, 2011) discuss the modeling of four types of wind turbines, i.e. with fixed, variable slip turbine generators, doubly-fed induction generators, and full converter turbine generators. In (Eremia and Shahidehpour, 2013), authors discuss mathematical models of wind turbine systems to illustrate tip speed as the ratio of peripheral speed and wind speed. Further, the authors suggest that it is very essential to limit the mechanical power produced by the wind turbine. The rated power must be kept in control and that is possible through introducing mechanisms such as pitch control, active stall control and passive stall control. The variable-speed turbines use pitch control that enables blades to turn into the wind direction when the wind speed is too low, and it turns the blades in other directions when the speed is too high for an emergency stop. Johnson et al. (Girsang et al., 2014) proposes that in order to efficiently utilize the power extracted through the wind, drivetrain plays a vital role. The wind turbine drivetrain consists of components that convert the kinetic energy of the wind into rotational kinetic energy and later into electrical energy as it is coupled to the generator through a transmission or gearbox. Johnson et al. (Johnson, 2001) models the wind turbine system using the power $P_{w}$ in the wind that passes through the turbine producing a mechanical power at an angular velocity denoted by $\omega_{m}$, which is later supplied to the transmission. However, the transmission converts the mechanical power into rotational kinetic energy, called torque. The torque produced by the drivetrain can be extracted out by dividing the transmission power into mechanical power.

Sarkar et al. (Sarkar and Behera, 2012) represented wind turbines with power and efficiency is measured at different tip speed. Wang et al. (Wang and Chiang, 2016), propose an approach to cosimulate the wind turbine system in MATLAB/SIMULINK. The design methodology increases the flexibility and control ability of wind turbines. Eberhart et al. (2015) presented an open-source library using Modelica language for wind power plants. It helps model and predicts an estimated generation, based on timedomain simulation.

In (Saini, 2013), the authors review the doubly-fed induction generators (DFIG) as it is the most widely used in wind turbine systems; its characteristics and properties that make it standalone from other generator are presented. Tapia et al. (2003) presented simulation results of doubly-fed induction machines connected to the grid at operating conditions above and below synchronous speed. It also includes the development of a mathematical model of wind generators to control the power factor. Gonzalo et al. (Abad et al., 2011), provided details of four different types of wind turbines available and then discusses dynamic modeling of doubly-fed induction machines, along with its steady-state analysis. The testing of doubly-fed induction machines and its analysis at voltage dip conditions are discussed with vector and direct control strategies. Marouan et al. (Elazzaoui, 2015) provided modeling and control of DFIG based wind turbine systems using a control vector flux. Another model uses Latin hypercube sampling method to produce uncertainty scenarios to analyze different demand response and applies Multi-objective optimization for hybrid energy system to satisfy electrical load (Ju et al., 2019). A similar work proposes a heuristic-based approach (Tabu Search) for Small scale hybrid power generation mix based on solar and wind energy with minimal life cycle cost using load forecasting (Zhang et al., 2019).

\subsection{Agent-based modeling frameworks}

ABM plays a vital contribution in the energy sector as generalized energy networks are modeled using ABM that proposes algorithms to calculate power flow in electric networks. Matteo et al. (Vasirani et al., 2013) proposed agent-based modeling of virtual power plants and integrated with electric vehicles to store energy and avoid the irregular nature of the energy supply. Mast et al. (2007) develop an agent-based approach to simulate different scenarios and implement large scale offshore wind power plants that include uncertainties of future and consequences of the decision. Enrique et al. (Kremers et al., 2011) integrated ABM with discrete events and dynamic systems approach to simulate the power of wind at different time instances. The modeling includes three different case studies such as low wind speed day, high wind speed day, and simulation over a week. Kramer et al. (Kraan et al., 2018) proposed an agent-based modeling technique to model investor's decision-making in the electricity sector. The model treats investors as agents and predicts solution based on carbon price 
scenarios and heterogeneous investor behavior. Gonzalez et al. (de Durana et al., 2014) propose an approach for modeling generalized energy networks through an agent-based method. It is a modular approach and allows the scalability and extensibility of models. Further, applications of the proposed framework include small microgrids to large energy systems. Paula et al. (Hansen et al., 2018) identify the research gap in the literature on agent-based modeling and energy transitions; based on an extensive review, the potentials of the agent-based modeling in energy transitions is divided into six areas covering different components of the energy system. Mahmood et al. (2020a) present an extensive review on a wide range of agent-based models that are used in simulating the demand and supply of energy at various resolutions. Furthermore they present a hierarchical, multi-resolution Agent Based Modeling and Simulation Framework for simulation long term energy Demand at residential level (Mahmood et al., 2019). Moreover, the distribution of the articles over different topics shows the continuous electricity market-related explorations. Further, choosing $A B M$ to energy transition complexities is shown in most of the articles; whereas, the rest of the articles shows that ABM set in the context of energy transitions. In model development, more interdisciplinary studies are recommended to report the differences between social practices and modeling of energy transitions. Sahnoun et al. (2015) describe wind turbine maintenance at offshore as complex and not cost-effective keeping in mind the factors such as the size of turbines, wind farms, distance from coastal areas and weather-related conditions. Therefore, it is difficult for stakeholders to determine the ideal maintenance strategy. The authors proposed a multi-agent hybrid model for the maintenance of wind turbines. They selected different maintenance strategies to analyzed them on the basis of the multi-criteria decision algorithm that is being developed for this purpose. They also presented the cost model that includes the cost of installation, monitoring, and maintenance cost.

\subsection{Discussion}

Most of the models presented in the literature review are monolithic, designed for a particular problem; therefore, difficult to extend to simulate large-scale complex scenarios. Thus, only limited scenarios can be simulated. Moreover, the existing work lacks component reusability due to the tightly coupled model. The components as rigidly connected with other components; thus, cannot allow an easy extension to add or remove components from the design. However, in existing work, the most commonly used framework/tools to simulate the agent-based systems are traditional programming languages, open-source Modelica, and Matlab toolkits. However, these tools provide limited scalability, support for multi-resolution modeling and no additional support for cloudbased simulation In this work, we propose a flexible agent-based component-oriented design for the rapid prototyping of wind power plants with a wider range of design flexibility and model reuse. The former allows quick modifications in the component specifications, whereas the latter offers component reuse in different settings to prototype design variations (Mahmood et al., 2019). Moreover, our choice to use Anylogic as an underlying 'Simulation Engine' offers numerous benefits such over tools used in existing work, such as (i) Multiresolution, multi-scale, hierarchical and modeling environment to simulate large-scale complex models (Mahmood et al., 2020a); (ii) A user-friendly model editing visual interface, that allows easy configuration and extensibility features; (iii) Large-scale, high-performance platform that can run on a standalone system or can be configured for the cloud-based runtime simulation environment. The next section covers the proposed work mathematical formulation and design.

\section{Proposed approach}

This section discusses our proposed approach and the salient features of the proposed framework. We describe the mathematical model and the component-based ABM framework that is used to model the characteristics and specifications of the wind turbine system under study. The section details the role of actors, interrelationships they posses, and their influencing environment that is used in modeling the wind turbine system.

\subsection{Mathematical model}

In this section we discuss a mathematical model, which is used to calculate the rotational kinetic power produced in a wind turbine at its rated wind speed e.g. minimum wind speed at which a wind turbine produces its rated power (Calculations, 2012). The power in the wind is given by the rate of change of energy:

$P=\frac{d E}{d t}=\frac{1}{2} \frac{d m}{d t} v^{2}$

As mass flow rate is given as, $\frac{d m}{d t}=\rho A v$ where $\rho$ is the mass density of the fluid, $A$ is the cross-sectional vector area/surface, and $v$ is the flow velocity of the mass elements. Hence, Equation (1) becomes:

$P=\frac{1}{2} \rho A v^{3}$

where $\rho$ is the air density $\left(\mathrm{kg} / \mathrm{m}^{3}\right), A=\pi R^{2}$ is the area swept by the rotor blades, $v$ is the average wind speed $(\mathrm{m} / \mathrm{s})$ passing through the surface, and $R$ is the wind turbine rotor radius (m).

In 1919 , a German physicist stipulated that not more than $59.3 \%$ of kinetic energy of wind is convert able into mechanical power. This is known as 'Betz limit' or Betz law. Therefore, the maximum theoretical power efficiency of any turbine is 0.59 . This maximum theoretical power efficiency is known as power coefficient denoted as $C_{p}$ (Wang and Chiang, 2016; Calculations, 2012). Hence, the power coefficient needs to be factored in as:

$P=\frac{1}{2} \rho A v^{3} C_{p}$

The power coefficient $C_{p}$ is not static and depends on the aerodynamic properties of the blades, that is $C_{p}$ is represented as a function $C_{p}(\lambda, \beta)$ in terms of the tip-speed ratio $\lambda$ and blade pitch angle $\beta$ as illustrated in Fig. 1. The tip-speed ratio $\lambda$ is defined as:

$\lambda=\frac{v_{b}}{v}$

where $v$ is average wind speed and $v_{b}$ is blade tip speed. Here, $v_{b}$ is defined as,

$v_{b}=\frac{\omega \pi D}{60}$

where $\omega$ is angular speed (rpm), and $D$ is the diameter of the turbine.

Finally, the amount of energy consumed $E$ during a period of duration $t$ is given as:

$E=P \times t$

To model the doubly-fed induction generator (DFIG), we use algebraic equations to calculate electrical power using Park Transformation that converts time varying differential equations to timeinvariant differential equations. The $a-b-c$ frame is changed to d-q 


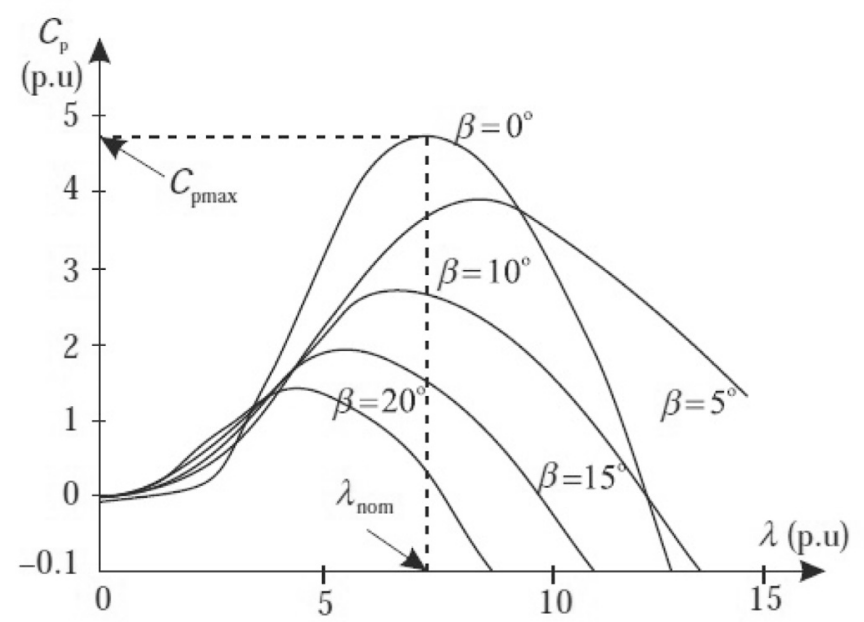

Fig. 1. $C_{p}$ for various blade pitch angles and tip-speed ratios (Eremia and Shahidehpour, 2013).

frame which calculate stator power and rotor power in $\mathrm{d}$ and $\mathrm{q}$ frame separately, then combines to get total electrical power. Stator voltages in d-q frame are calculated using equations below:

$\mu_{d s}=-R_{s} i_{d s}-\omega_{s} \psi_{q s}+\frac{d \psi_{d s}}{d t}$

$\mu_{q s}=-R_{s} i_{q s}+\omega_{s} \psi_{d s}+\frac{d \psi_{q s}}{d t}$

Similarly, rotor voltages in $\mathbf{d - q}$ frame are calculated using equations below:

$\mu_{d r}=-R_{r} i_{d r}-S \omega_{s} \psi_{q r}+\frac{d \psi_{d r}}{d t}$
$\mu_{q r}=-R_{r} i_{q r}+S \omega_{s} \psi_{d r}+\frac{d \psi_{q r}}{d t}$

where $\mu$ represents voltage, $R_{S}$ denotes stator resistance, i represents current, ds represents $\mathrm{d}$ frame and qs represents q frame of stator, $\omega$ is angular speed, $S$ slip defines the relative speed of the generator rotor compared with that of stator, $L$ is inductance and $\psi$ is the flux, and given as:

$\psi_{d s}=-L_{s s} i_{d s}-L_{m} i_{d r}$
$\psi_{q s}=-L_{s s} i_{q s}-L_{m} i_{q r}$
$\psi_{d r}=-L_{r r} i_{d r}-L_{m} i_{d s}$
$\psi_{q r}=-L_{r r} i_{q r}-L_{m} i_{q s}$

where $L_{s s}$ is stator inductance, $L_{r r}$ is rotor inductance and $L_{m}$ is mutual inductance. Simple algebraic equations yields flux of stator and rotor in d-q frame to be used in Equation (8) to calculate voltage.

The total active $P$ and reactive $Q$ powers exchanged by the DFIG with the electrical network are the sum of the stator and rotor powers:

$P=P_{s}+P_{r}$

$Q=Q_{s}+Q_{r}$

Where
$\left\{\begin{array}{l}P_{s}=\mu_{d s} i_{d s}+\mu_{q s} i_{q s} \\ P_{r}=\mu_{d r} i_{d r}+\mu_{q r} i_{q r} \\ Q_{s}=\mu_{q s} i_{d s}-\mu_{d s} i_{q s} \\ Q_{r}=\mu_{q r} i_{d r}-\mu_{d r} i_{q r}\end{array}\right.$

Set of equations represented in Equation (11) shows power calculation of active and reactive power in stator and rotor of designed DFIG. The equation exhibits the power formula that is product of voltage and current in $d$ and $q$ frame. Since, it is common fact that inductance, reactance and resistance has a direct relation with temperature so when temperature increases in generator then values of stator and rotor inductance and resistance do change and this phenomenon is also catered in a function named as 'Temperature Effect' in Generator Agent to make our simulation model smart enough.

\subsection{Agent-based component models}

We propose the use of component-based modeling approach to develop reusable components in the form of agent and compose them together to build the complete wind power plant system. Proposed agent-based components are modeled using Anylogic simulation software: (i) turbine (ii) anemometer (iii) rotor (iv) pitch drive (v) drivetrain, and (vi) generator. All agents function together to predict electricity generation produced against provided wind speed. The model is set on hourly resolution therefore, forecasts energy production accordingly.

\subsubsection{Turbine agent}

Turbine is the core of wind power plant that captures wind speed, converts it into suitable magnitude to get the required output power. We populated 20 turbine agents to create the wind Farm. The turbine contains its components as agents and are shown in Fig. 2.

It shows the components of agents composed under a turbine agent in a hierarchical fashion. Furthermore, a state machine of wind turbine is constructed to process and control set parameters, timeout and conditions, shown in Fig. 3. This state chart presents the behavior of a turbine and handle planned maintenance and downtime due to failures.

The set parameters are obtained from the Nordex N100/2500 specifications. The state machine consists of following three states:

(a) ON: When in this state, the turbine is active and generates output power; no matter the turbine is partially loaded or fully loaded

(b) OFF: When in this state the turbine generates no output power. This state occurs either when wind speed is very high or very low because turbine is designed to switch off under this scenario. Turbine checks its condition of switch off and halts operation when it gets true.

(c) Failure: When in this state, the turbine shuts down either for maintenance purpose or when there is some failure. For efficient working of this state, two parameters are defined: maintenance and failure probability. Therefore, the set value of parameter maintenance is three, as the turbine requires $3 /$ $24 \mathrm{~h}$ for maintenance purpose whereas the failure probability of turbine is set to be 0.025 .

Turbine agent further consists of the following agents for anemometer, rotor, pitch drive, drivetrain, and generator discussed below. 


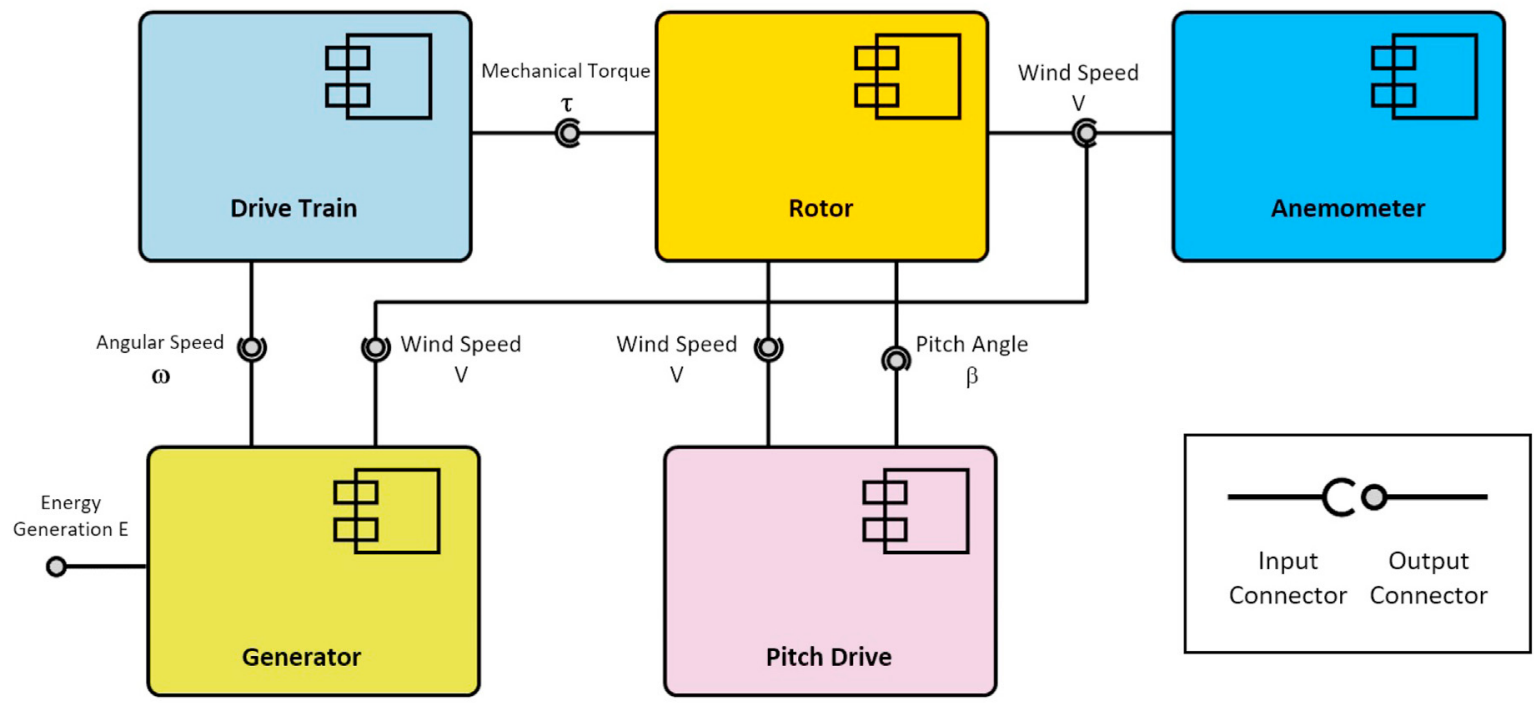

Fig. 2. Component diagram of turbine agents.

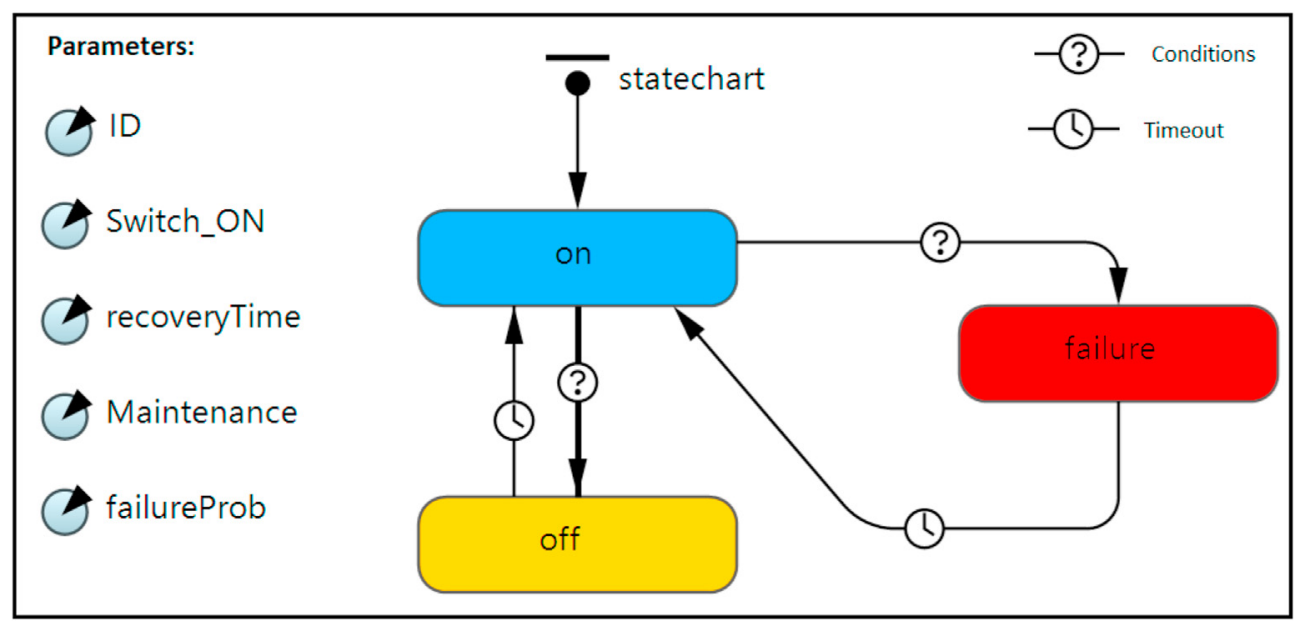

Fig. 3. State machine of turbine.

\subsubsection{Anemometer agent}

Anemometer publishes wind speed data at an equal interval of time, according to the set time resolution (currently it is set to hourly resolution). This data is used by other components to function. We have used two methods to implement anemometer: (i) historical wind: It takes past wind speed data as input and generates the historical wind speeds on the simulation time line; and (ii) simulated wind: It generates random samples using Weibull distribution to simulate future wind (Department, 2005). Anemometer agent shown in Fig. 4 has two variables named as

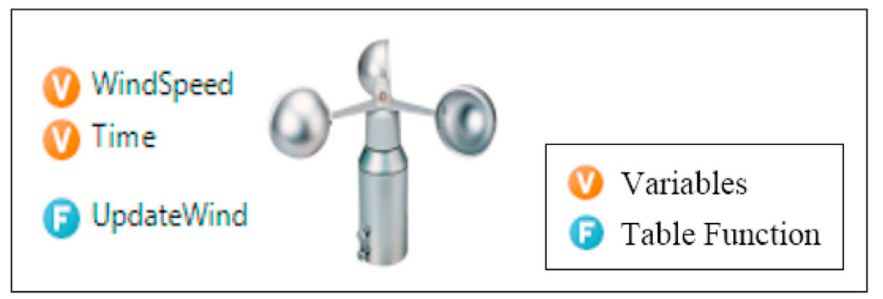

Fig. 4. Anemometer agent.
WindSpeed and Time where the first one contains initial value of wind speed and later contains the initial time whereas the function Update Wind() updates wind speed after every hour, and supplies it to the agent rotor. It reads the wind speed from the database.

The wind speed is on hourly resolution and is provided by Foundation Wind Energy Private Limited. The graph plot of wind speed data for the two months of the year 2018 aggregated at an hourly resolution is shown in Fig. 5.

\subsubsection{Rotor agent}

The rotor agent is the main component of wind turbine. Blades of turbine capture kinetic energy of wind and convert it into mechanical power. Nordex N100/2500 turbine contains three blades with a diameter of $99.8 \mathrm{~m}$, making its radius to be $49.9 \mathrm{~m}$ and swept area (swept area is the area in which the rotor sweeps in a circular motion and is the plane of wind by the generator) equals to $7823 \mathrm{~m}$. Rotor rotates when wind speed is between $3 \mathrm{~m} / \mathrm{s}$ to $25 \mathrm{~m} / \mathrm{s}$, rendering $3 \mathrm{~m} / \mathrm{s}$ as cut-in speed and $25 \mathrm{~m} / \mathrm{s}$ as cut-out speed of wind turbine. State machine for rotor is shown in Fig. 6 and contains the following three states for turbine's rotor. 


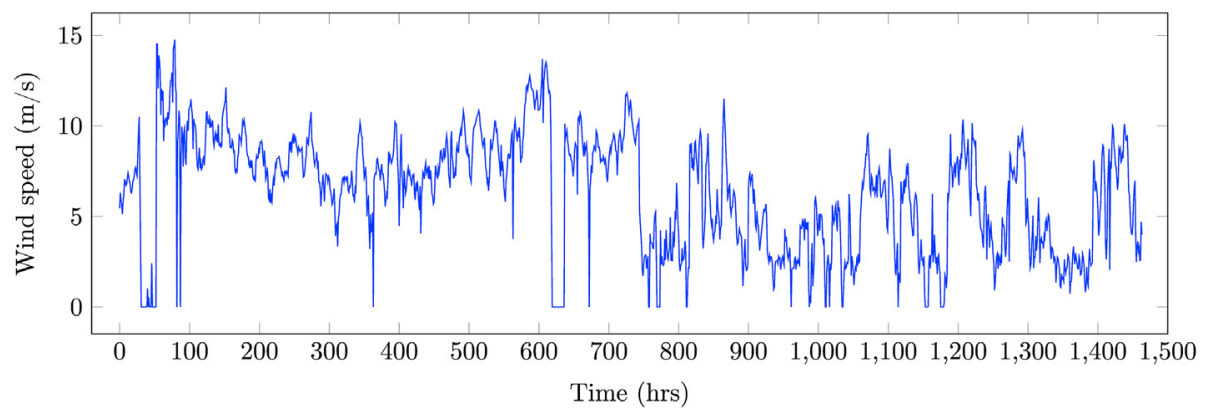

Fig. 5. Graph plot of provided wind speed.

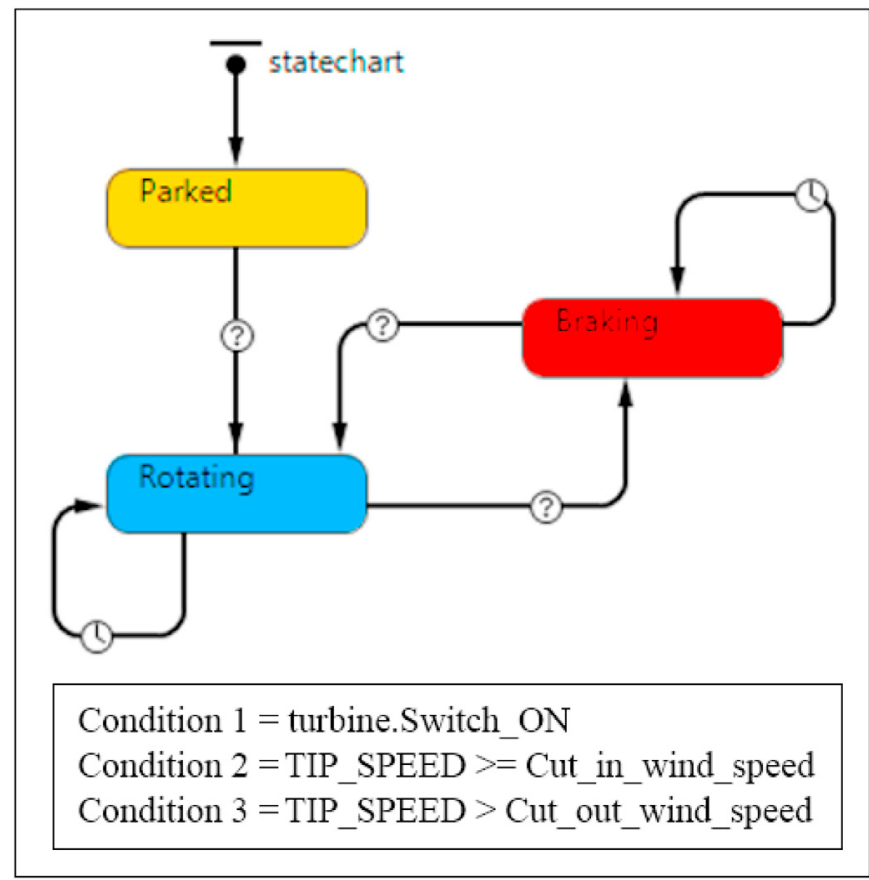

Fig. 6. State machine of rotor agent.

(a) Parked: When the turbine is in inactive state such that its switch on condition is false then turbine rotor is in parked state and goes to rotating state when condition of turbine's switch on gets true.

(b) Rotating: This state converts kinetic energy of the wind into mechanical power and triggers itself after every minute.

(c) Braking: This state gets active when wind speed exceeds the cut-out speed and remains in it unless wind speed is equals to or greater than cut-in speed. The state checks itself after every 1 min to determine which state is to be acquired next. Soon after the wind speed is greater than or equals to cut-in speed, it goes back to rotating state.

\subsubsection{Pitch drive agent}

Pitch drive is the control strategy in wind turbine systems that limits the mechanical power by turning the blades into or out of wind gust direction when either wind speed is too low or too high. The angle varies between 0 and $25^{\circ}$. Our proposed simulation model contains pitch drive agent that uses an optimization function to calculate the optimal pitch angle $\beta$ for which the highest power coefficient can be achieved. There is only one state in this agent which is continuously updated with the self-loop transition 'UpdatePitchAngle', that keeps on calculating the optimal pitch angle using the current value of the tip speed ratio, as shown in Fig. 7.

Power coefficient characteristics for different blade pitch angles $B$ defined in our simulation model and are shown in Fig. 8.
By obtaining a suitable $\beta$ angle against a given tip speed ratio, we get optimal value of $C_{p}$ that is used to calculate the mechanical power using Equation (3).

\subsubsection{Drivetrain agent}

Drivetrain converts mechanical power into rotating torque that is fed into the generator to produce electrical energy. State machine of drivetrain agent consists of following two states and is shown in Fig. 9.

(a) OFF: This state is active when turbine is not active and triggered every minute to check current state.

(b) ON: This state is active when turbine is in active state and turbine rotor is in rotating state.

When state on is active, drivetrain calculates torque using,

Torque $=\frac{P t}{P m}$

This torque is fed into electrical generator.

\subsubsection{Generator agent}

Induction generator is widely used in wind turbines because it is good in performance, lightweight and low-priced. The torque produced by wind turbine drives the generator rotor. This generator needs a reactive magnetizing current to excite itself and selfexcitation is made possible providing the initial excite from a capacitor bank instead of connecting it to the main grid. Active power created by the generator has a direct relation with slip and slip is defined as the difference between generator rotor speed and generator stator speed. The torque produced by the wind turbine rotates the generator rotor so its angular speed is dependent on it. When the wind speed is too little to produce electrical energy out of it then generator acts as a motor and absorbs energy from the grid, for this purpose, it is usually detached from the grid. The rotor of induction machine is either squirrel cage or wound rotor (Press et al., 2013). A wound rotor induction machine having variable rotor voltage frequency replaces synchronous generators that are interfaced with grids to get a static frequency to produce a constant electrical power whenever a variable speed generation is concerned. The mechanical power captured by the wind turbine is fed into the DFIG (Fig. 10) that is connected to the grid and has back-toback converters attached with it. These are voltage source converters that converts $A C$ source voltage coming from the rotor side to DC source voltage and then converts DC source voltage to AC source voltage at grid parameters as output. These converters are connected by a dc link capacitor. The rotor side converter controls speed of DFIG and power factor while the stator side converter keeps the dc link voltage constant. Stator is connected directly to the grid whereas rotor needs a step down transformer to get 


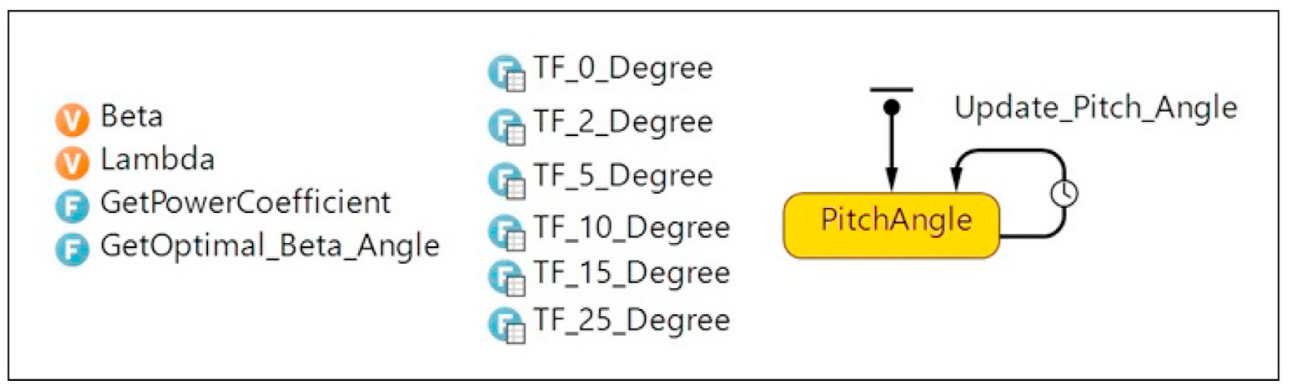

Fig. 7. Pitch drive agent.

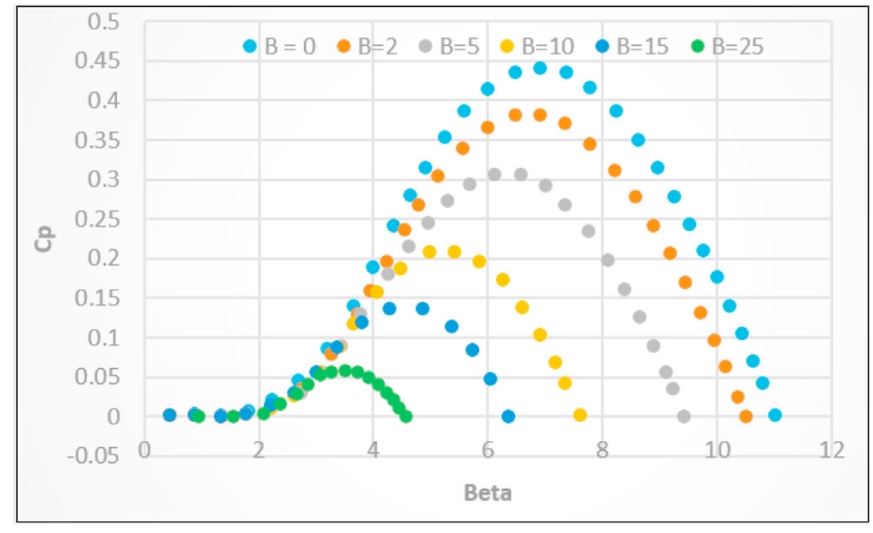

Fig. 8. Optimal value of $C_{p}$ against maximum value of $\beta$.

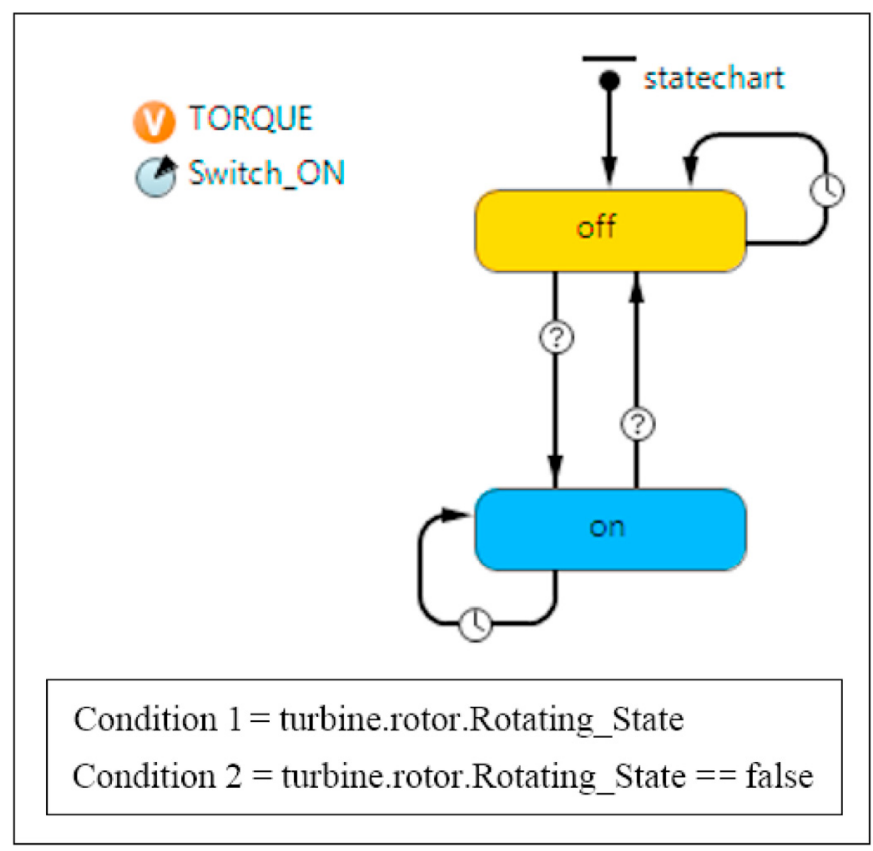

Fig. 9. State machine of drivetrain agent.

connected with the grid. Energy obtained by wind is fed into the network by both stator and rotor in order to enable a normal generation scheme (Valipour et al., 2016; Saini, 2013).

Generator agent converts torque calculated in drivetrain agent into electrical power. The agent has following two states. (a) OFF: State remains off when the drivetrain agent's switch on is false and state is being triggered after every minute

(b) ON: Agent acquires this state when drivetrain agent is on and torque is being calculated and gained by generator agent. The state is also triggered every minute.

The agent starts calculating mathematical equations of DFIG given in Section 3.1. Stator and rotor voltages in $\mathrm{d}-\mathrm{q}$ frame are calculated using values stored in parameters shown in Fig. 11. The voltage equations are multiplied with respective currents to obtain stator and rotor power using Equation (11). The values of both powers at different instance of time are stored in tabular functions SPower() and RPower(). The addition of both powers results in providing us with total electricity generation produced by generator and the values of electrical power is stored in variable Electrical_Power. Temperature effect on inductance, reactance and resistance is catered in a function Temperature Effect() in generator agent to make our simulation model accurate enough to inculcate real time parameters. Therefore, the temperature effect is created using a function body that variate value of reactance and inductance accordingly.

\subsection{Model composability}

We initialize our turbines using Nordex N100/2500 wind turbine data as shown in Table 1. Each turbine has a capacity to produce 2.55 MW of energy. Parameters provided in prescribed turbine's brochure are followed to get optimal depiction of it. These set parameters are incorporated in agents to model our proposed framework in accordance with the real time system (such as Foundation Wind Energy power plant (FWEL, 2019)). Therefore, an agent-based simulation model is represented in which every agent is interlinked with one another in a hierarchical fashion under the main turbine agent. The components are composed ports in Anylogic environment as shown in Fig. 2. The moment turbine switch is on; rotor goes into rotating state, captures kinetic energy from wind rotor in the rotating state, and converts kinetic energy into mechanical power. Soon after the rotor goes into the rotating state, pitch drive starts analyzing the tip speed ratio and $\beta$ angle to provide maximum value of $C_{p}$ to extract maximum power from wind energy. Turbine drivetrain gets active when rotor goes into rotating state. Drivetrain in on state converts mechanical energy into torque to transfer it to the generator whereas generator calculates the stator power and rotor power separately and sums them up, to extract the active power generated through wind speed. The model halts its operation at the time of turbine failure or maintenance or when wind speed increases above cut-out speed that is $25 \mathrm{~m} / \mathrm{s}$ or decreases below cut-in speed that is $3 \mathrm{~m} / \mathrm{s}$. Therefore, no electricity is produced until wind speed gets normal and within range of $3 \mathrm{~m} / \mathrm{s}$ to $25 \mathrm{~m} / \mathrm{s}$ or maintenance of wind turbine is performed. The 


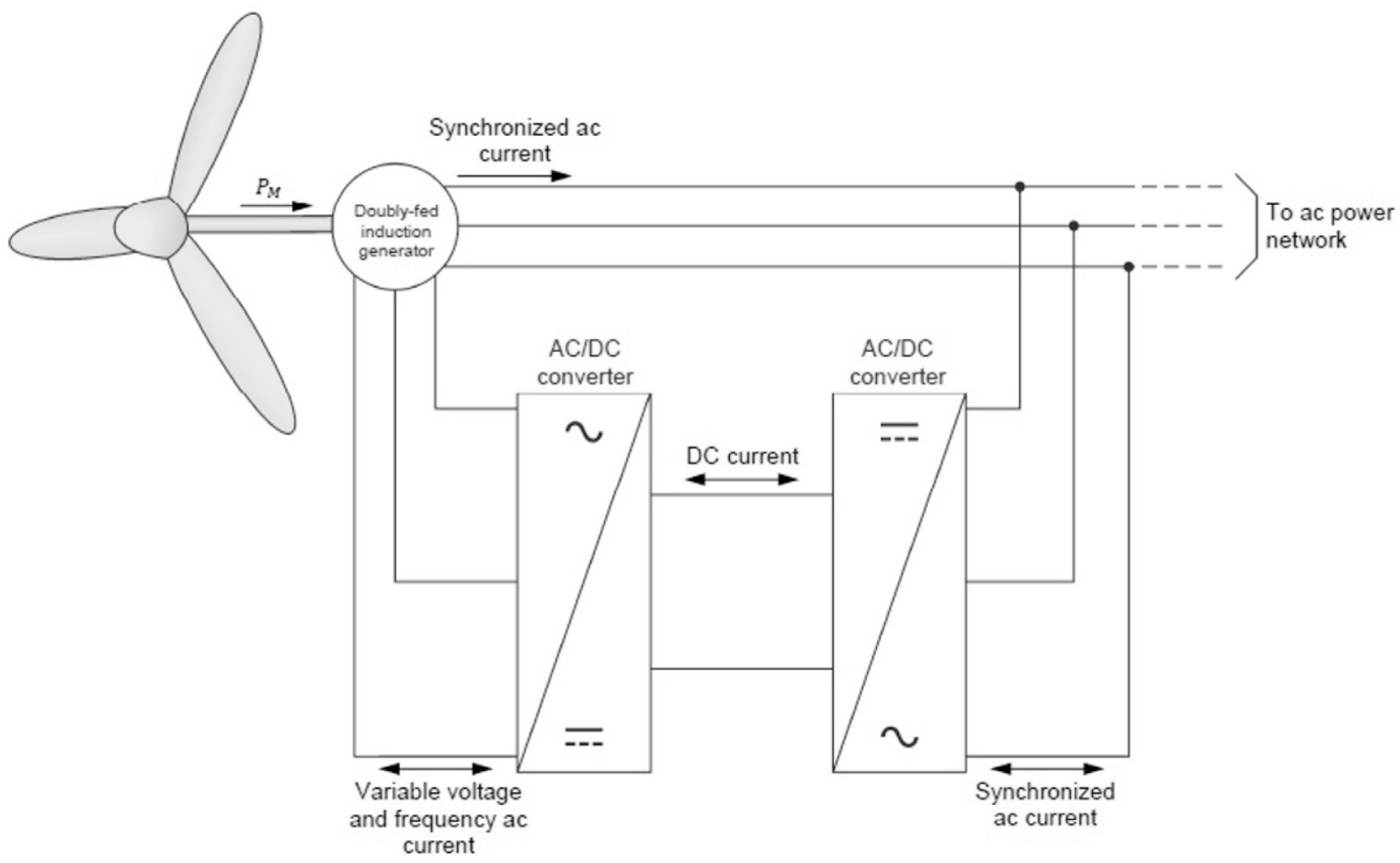

Fig. 10. Doubly-fed induction generator (Didacticet al., 2011).

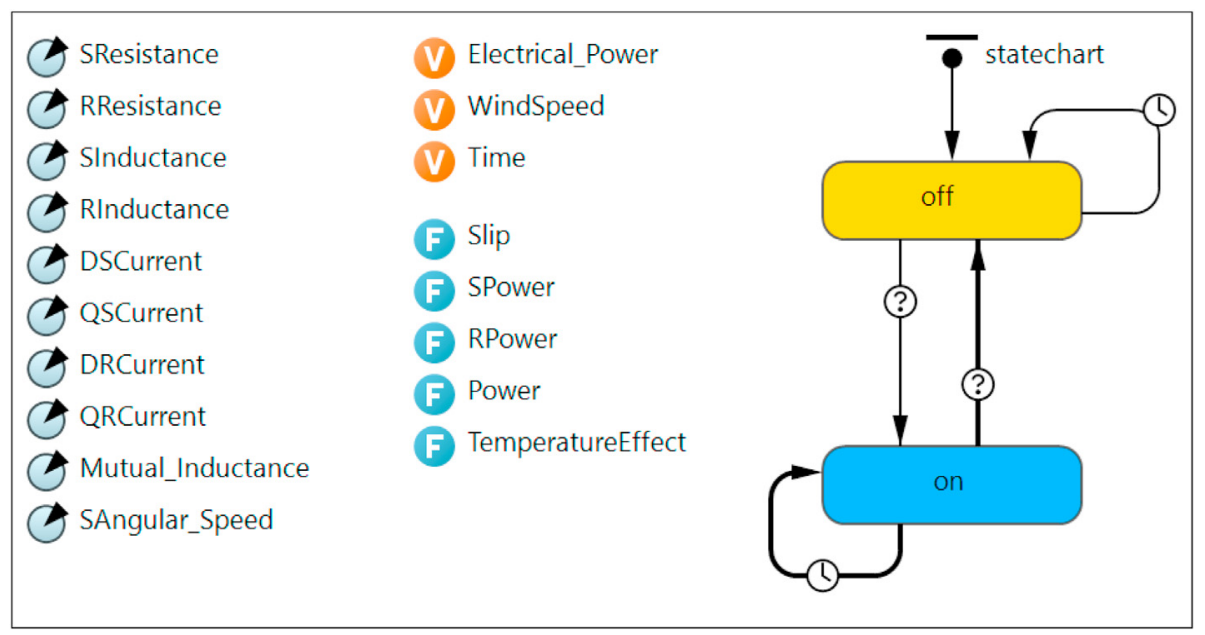

Fig. 11. State machine of generator agent.

Table 1

Specifications of Nordex N100/2500 wind turbines.

\begin{tabular}{ll}
\hline Operation & \\
\hline Rated power & $2500 \mathrm{~kW}$ \\
Cut-in wind speed & $3 \mathrm{~m} / \mathrm{s}$ \\
Cut-out wind speed & $25 \mathrm{~m} / \mathrm{s}$ \\
Rotor & \\
Diameter & $99.8 \mathrm{~m}$ \\
Swept area & 7823 \\
Overspeed control & Pitch angle \\
Generator & \\
Construction & Doubly-fed induction generator \\
\hline
\end{tabular}

simulation results are discussed in detail in next section.

\section{Case study}

In this section, we present the details of our case study, based on the Foundation Wind Energy Private Limited (FWEL, 2019) whose SCADA data of actual generation and wind speeds are used to validate our simulation model. The plant is set up by Fauji Foundation group and is located at Mirpur Sakro, Sindh, Pakistan. The total installed capacity of the plant is $50 \mathrm{MW}$ and contains twenty turbines of Nordex N100/2500. The micro sitting of the power plant is shown in Fig. 12.

Each turbine has capacity to produce $2.5 \mathrm{MW}$. The rated power is attained at $12 \mathrm{~m} / \mathrm{s}$ and produces constant power onward until wind 


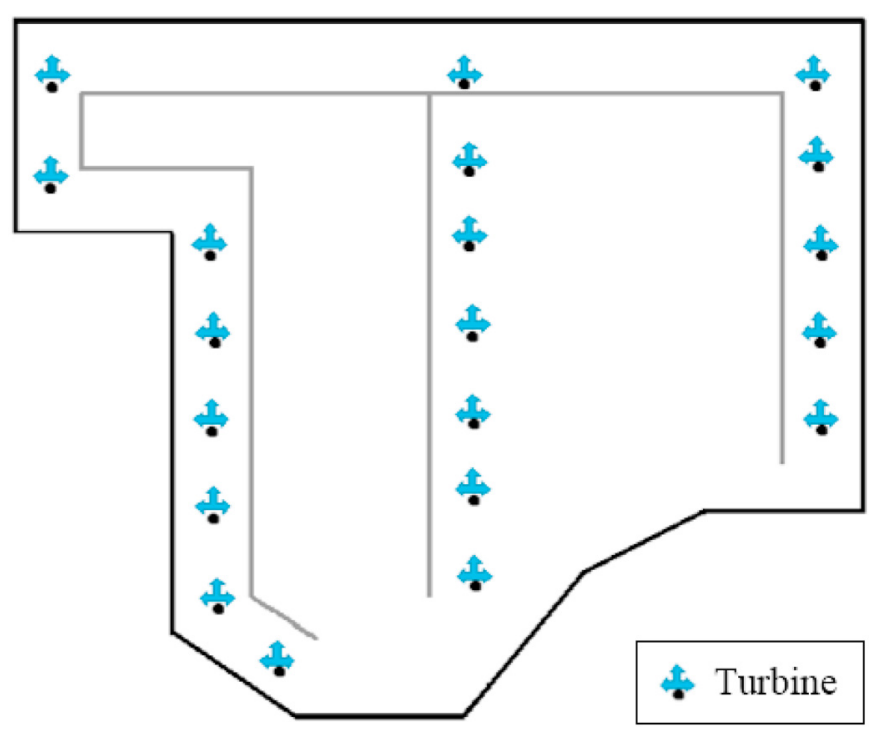

Fig. 12. Micro sitting of wind farm.

speed reaches cut-out speed. The turbine is designed to halt its operation on reaching cut-out wind speed such as $25 \mathrm{~m} / \mathrm{s}$. The power curve versus wind speed for Nordex N100/2500 ${ }^{1}$ at air density $1.160 \mathrm{~kg} / \mathrm{m}^{3}$ is shown in Fig. 13.

\subsection{Nordex N100/2500 wind turbine}

Nordex N100/2500 is designed to be used in areas with moderate wind conditions and widely different climatic conditions that lies under Gamma Generation. The gamma generation turbines achieve maximum yield at almost every site, maintains voltage, and stabilize frequency of the public grid by outstanding control capabilities. The specifications of Nordex N100/2500 are shown in Table 1.

\subsection{SCADA data of foundation wind power plant}

The SCADA data obtained is of power generated against available wind speed for two months (High Wind and Low Wind). However, it was observed that the trends remain same throughout the year for each category. Fig. 14 shows the actual power produced at wind farm of Foundation Wind Energy Private Limited against available wind speed where $\mathrm{x}$-axis represents time and $\mathrm{y}$-axis shows actual generation in MW.

\section{Simulation results and validation}

\subsection{Simulation procedure and results}

This section provides simulation results of our proposed framework. The simulation model runs in accordance with the provided parameters and generator capacity. The designed generator's output graph versus wind speed is shown in Fig. 15. The curve shows a gradual increase in power generation as the wind speed increases. The lowest value of power production is $1700 \mathrm{~W}$ at $3 \mathrm{~m} / \mathrm{s}$ and rated power of $2.5 \mathrm{MW}$ is achieved at $13 \mathrm{~m} / \mathrm{s}$ and continues until speed reaches $25 \mathrm{~m} / \mathrm{s}$.

The simulation generation pattern of complete wind power

\footnotetext{
1 https://www.thewindpower.net.
}

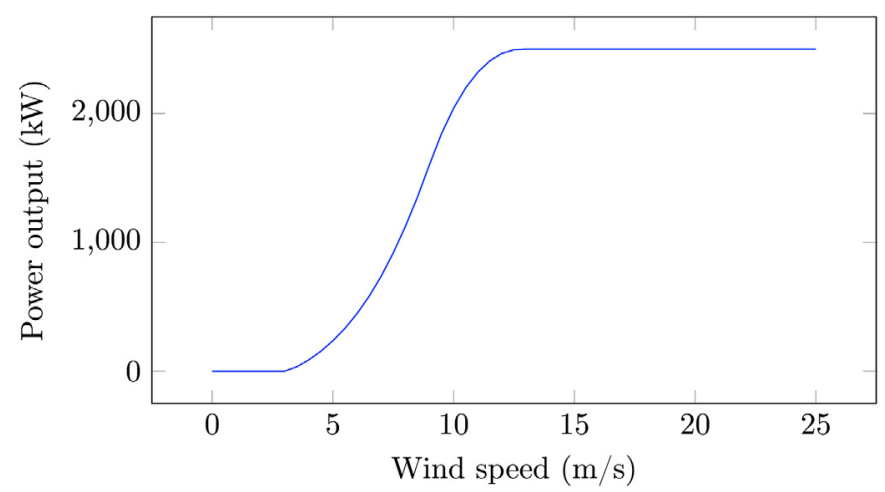

Fig. 13. Power versus wind speed at air density $1.160 \mathrm{~kg} / \mathrm{m}^{3}$.

plant is the combined effect of the interaction of individual turbines and shows energy generation trend of simulated power plant. The energy curve shows maximum rise up to $50 \mathrm{MW}$ (equals to installed capacity of wind power plant) and is shown in Fig. 16. It is evident from simulation results that there is no generation of electricity at wind speed below cut-in and above cut-out wind speed.

\subsection{Model validation}

The model is validated by plotting simulation results over the actual generation data as shown in Fig. 16. The graph plot shows minor difference of simulated generation from actual generation, however the trend lines nearly fit each other. The simulation run for wind power plant produces maximum power of $50 \mathrm{MW}$ whereas actual generation is up to $49.5 \mathrm{MW}$. The RMSE value calculated is $\sim 9 \mathrm{MW}$ as shown in Table 2.

We also perform a time series analysis on actual data to get a fitted model, which is compared against our simulation results. Starting with a sequence of discrete-time data taken at successive equally spaced intervals indexed in chronological order, the analysis fits a model to predict future values based on previously observed values. In this study, the analysis is used for short-term power generation forecasting. More specifically, we focus on statistical models because they are easier to use and cheaper to develop compared to sophisticated weather models. Generally, the models use analysis of historical time series data to make forecasts. Often they use traditional statistical approaches, and more recently there is a focus on so-called learning approaches. Nonetheless, a common attribute of any statistical and learning approach is the use of large amounts of historical data, establishing links among the time-series data points for forecasting.

For instance, we use the additive seasonality version of the standard Holt-Winters exponential smoothing for forecasting seasonal time series, which is a within-week seasonalities in power generation. Note that the additive version is used when seasonal variations are independent of the current mean level. For the time series analysis, we take a within-week seasonal cycle of duration $168 \mathrm{~h}$ periods for the analysis. We identify the most suitable model fitted on the actual hourly power generation data as shown in Fig. 17.

In addition to standard Holt-Winters additive method, we use four other methods for time series forecasting including Croston model, Teunter-Syntetos-Babai (TSB) model (Teunter et al., 2011), autoRegressive integrated moving average (ARIMA) model, and learning-based time-series forecasting with long short-term memory network (LSTM). Similar to Holt-Winters forecasting presented earlier, Fig. 18 shows the forecasting model fitted on the 


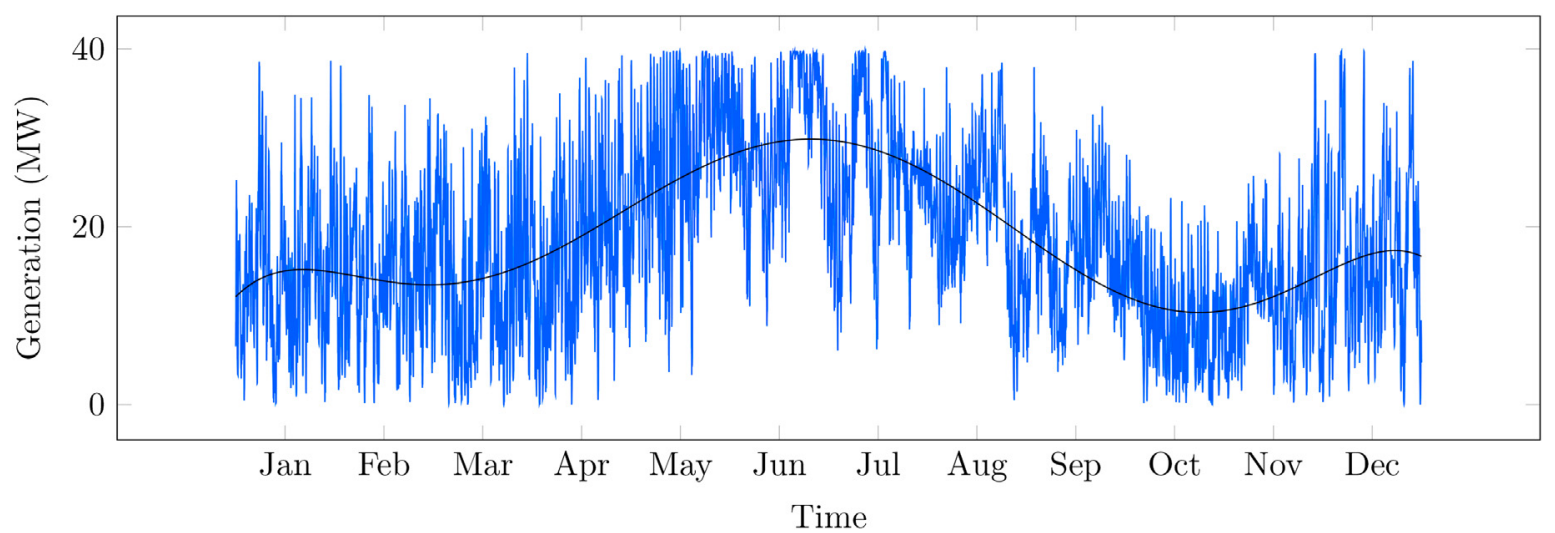

Fig. 14. Actual generation in MW of foundation wind power plant.

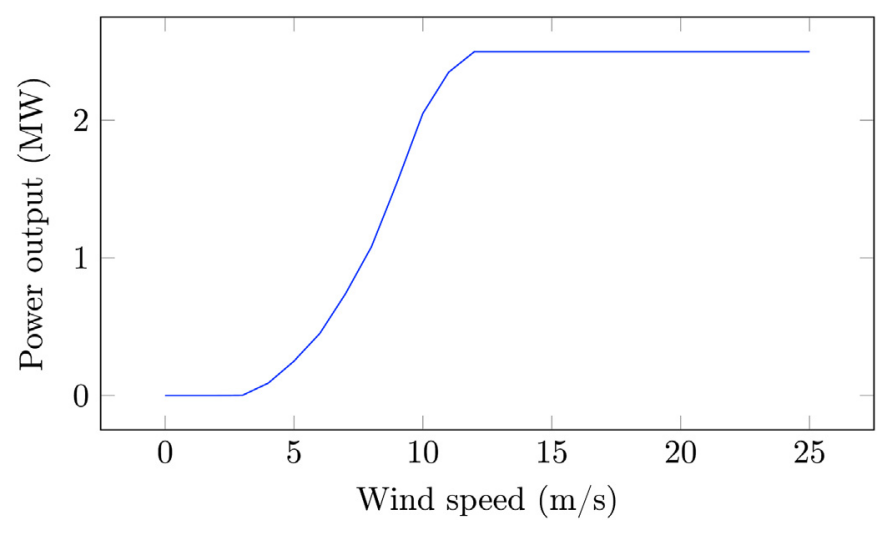

Fig. 15. Generator power output versus wind speed.

actual hourly power generation data. The results demonstrate that the wind energy forecasts from the simulation correspond to actual wind energy production. We measure the forecasting accuracy of the simulation model and time series analysis using different error summary measures including mean absolute deviation (MAD), root mean square error (RMSE), mean absolute percentage error (MAPE), and mean signed difference (MSD). The results listed in Table 2 demonstrates that forecasting errors from the simulation model are comparable to those from the seasonal time series analysis, except for MAPE. This is most probably due to the simulation model making unbiased forecasts in contrast to biased forecasts from the time series analysis, and unfortunately, MAPE
Table 2

Comparison of error summary measures for forecasting from the simulation model and different forecasting models for time series analysis.

\begin{tabular}{lllll}
\hline Analysis & MAD & RMSE & MAPE & MSD \\
\hline Simulation & 6.219 & 9.336 & 45.226 & 0.824 \\
Holt-Winters & 3.455 & 5.773 & 25.128 & 0.709 \\
Croston & 3.359 & 6.758 & 24.430 & -1.386 \\
TSB & 2.153 & 3.215 & 15.655 & -0.035 \\
ARIMA & 2.521 & 3.653 & 17.317 & 0.537 \\
LSTM & 2.336 & 3.775 & 17.900 & 0.018 \\
\hline
\end{tabular}

treating overforecasts differently than underforecasts.

\subsection{Analysis and discussion}

The simulation results show that the model is correctly representing the generation patterns of the actual site under observation. It can be observed from the simulations that the runs are in accordance with the provided parameters and generator capacity. The simulation generation pattern of complete Wind Power Plant is replicated using agent based approach that aggregates the dynamic agent behavior of twenty turbines and shows energy generation trends of the simulated power plant using the wind speed inputs. The unique feature of the proposed approach is the bottom-up approach of the component integration a their ability to interplay with each other in-order to synthesise the forecast. This mainly relies on the parameters, assumptions and the physical phenomenon of the wind energy production as opposed to the data-driven approaches which mainly rely on the availability of the data, and

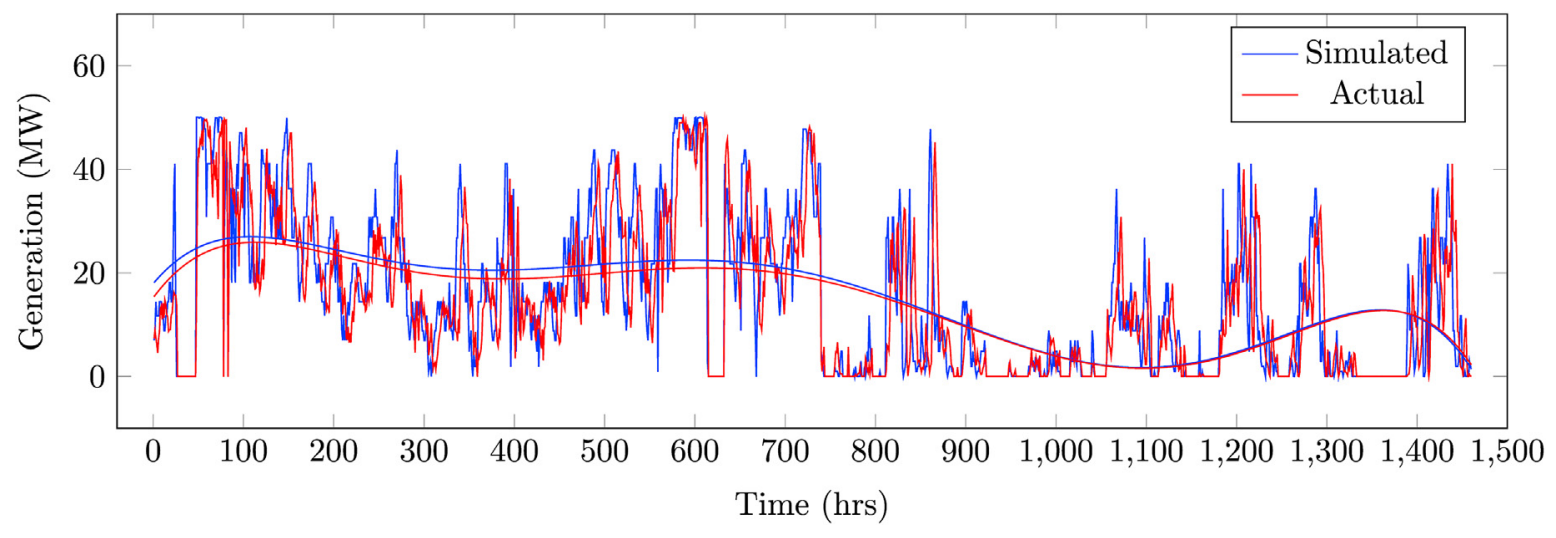

Fig. 16. Simulated generation versus actual generation. 


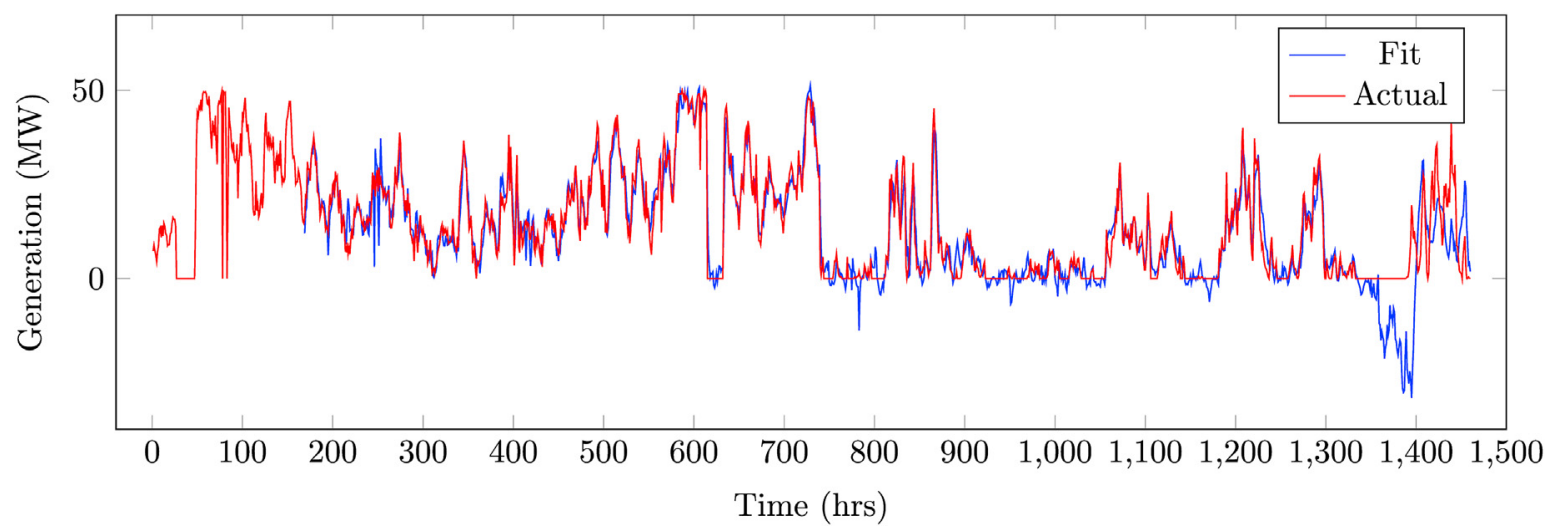

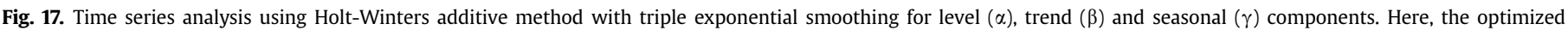
parameters minimizing RMSE are: $(\alpha, \beta, \gamma)=(0.464,0.002,1)$.

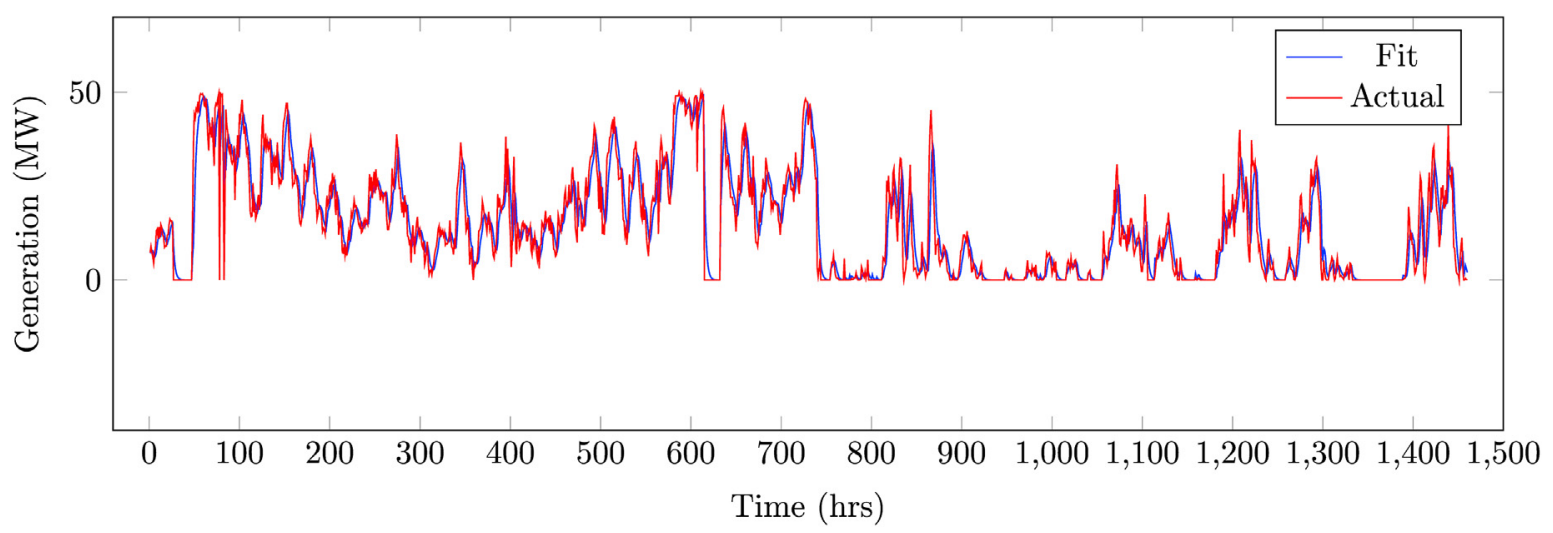

Fig. 18. Time series analysis using Teunter-Syntetos-Babai (TSB) method with smoothing constants $(\alpha, \beta)=(0.4,0.4)$.

particularly fail when the data is missing or sparse. Besides, it is easier to generalize the proposed approach for different power plants settings and therefore provide significant benefits in terms of model reuse.

To determine the effectiveness of forecasting model, four error statistics are measured as shown in Table 2. In terms of mode validation, lower error values are preferred. TSB acts as a better predictor given its forecasting results. To assess the significance of the differences among the forecasting models, we perform a twotailed $t$-test with confidence level $1 \%$, and observe an insignificant difference in forecasting performance. This demonstrates the effectiveness of the simulated model in comparison to different statistical forecasting models.

The framework has a tremendous utility for developing countries like Pakistan because such countries lack a strategic energy plan. The framework functions as a tool to explore the technical feasibility and economic viability of wind power systems, which in turn provide decision support to implement a more effective and less carbon-intensive mixed energy plan. Moreover, the renewable energy generation industry in Pakistan is in an immense need of such frameworks, to carry out what-if analysis on their power plant designs, control, and management schemes using model-based engineering. They can compose different model components of the power plants and evaluate the overall system efficiency before actual implementation to explore the future of renewable energy systems.

\section{Conclusion}

The proposed agent-based modeling and simulation framework for the rapid prototyping of wind power plants abstracts active components of wind power-plants and implements their dynamic behavior through interactions. The work relay on composing various components, design valuation, for forecasting energy generation cost-effectively and productively. To validate the model, the generated short and long-term electricity profiles are validated with the actual data. Whereas the minor difference has been observed when compared with the simulation-based and actual generation, however, the trend lines nearly fit each other. Further, different error measures are computed to evaluate the forecasting accuracy of the proposed model. The proposed work facilitates decision-makers in estimating the extent of electrical energy produced at given conditions using the wind potential available at the corridors of any country. It can further aid in terms of realistic analysis of the future dynamics of electricity demand and supply, hence help in energy planning. Moreover, the regulatory authorities can use the proposed model to determine the wind potential in Pakistan that can be used for electricity generation. In future, we intend to extend the proposed framework for different Wind Power Plants to forecast their energy generation patterns at different instance of time. This will allow Energy Generation sector to get a better insight of their Wind Power Plant's production capacities. 


\section{CRediT authorship contribution statement}

Imran Mahmood: Conceptualization, Conception and design of simulation, Funding acquisition, Data curation, Acquisition of data, Revising the manuscript, Writing - original draft, Drafting the manuscript, Approval of the version of the manuscript to be published. Mahe Mobeen: Conceptualization, Conception and design of simulation, Funding acquisition, Data curation, Acquisition of data, Approval of the version of the manuscript to be published. Anis Ur Rahman: Funding acquisition, Acquisition of data, Formal analysis, Data curation, Analysis and/or interpretation of data, Revising the manuscript, Writing - original draft, Drafting the manuscript, Approval of the version of the manuscript to be published. Shahzad Younis: Conceptualization, Conception and design of simulation, Approval of the version of the manuscript to be published. Asad Waqar Malik: Formal analysis, Data curation, Analysis and/or interpretation of data, Revising the manuscript, Writing - original draft, Drafting the manuscript, Approval of the version of the manuscript to be published. Muhammad Moazam Fraz: Revising the manuscript, Writing - original draft, Drafting the manuscript, Approval of the version of the manuscript to be published. Kafait Ullah: Revising the manuscript, Writing - original draft, Drafting the manuscript, Approval of the version of the manuscript to be published.

\section{Declaration of competing interest}

The authors declare that they have no known competing financial interests or personal relationships that could have appeared to influence the work reported in this paper.

\section{Acknowledgments}

This work is funded by US-Pak Center for Advanced Studies in Energy (USPCASE) under the Applied Research Grant ARG 004 project titled: "Simulation Modeling, Analysis and Forecasting of Electricity Generation in Pakistan using System Dynamics Approach".

\section{References}

Abad, G., Lopez, J., Rodriguez, M., Marroyo, L., Iwanski, G., 2011. Doubly Fed Induction Machine: Modeling and Control for Wind Energy Generation, Vol. 85. John Wiley \& Sons.

Alvi, M.S.Q., Mahmood, I., Javed, F., Malik, A.W., Sarjoughian, H., 2018. Dynamic behavioural modeling, simulation and analysis of household water consumption in an urban area: a hybrid approach. In: Proceedings of the 2018 Winter Simulation Conference. IEEE Press, Piscataway, NJ, USA, pp. 2411-2422.

Calculations, W.T.P., 2012. Rwe Npower Renewables, Mechanical and Electrical Engineering Power Industry. The Royal Academy of Engineering.

Castillo, M., Morales, G., Loyola, L.A., Singh, I., Calvo, C., Holland, H.L., MacLean, D.B., 1976. The alkaloids of L. paniculatum and the structure of paniculatine. Can. J. Chem. 54 (18), 2900-2908.

Chu, S., Majumdar, A., 2012. Opportunities and challenges for a sustainable energy future. Nature 488 (7411), 294-303.

Department, P.M., 2005. Ministry of Science and Technology, an Investigation on Wind Power Potential of Gharo.

Didactic, F., et al., 2011. Principles of Doubly-Fed Induction Generators (Dfig). Festo Didactic Ltee/Ltd.

de Durana, J.G., Barambones, O., Kremers, E., Varga, L., 2014. Agent based modeling of energy networks. Energy Convers. Manag. 82, 308-319.

Eberhart, P., Chung, T.S., Haumer, A., Kral, C., 2015. Open source library for the simulation ofWind power plants. In: Proceedings of the 11th International Modelica Conference, Versailles, France, September 21-23, 2015, pp. 929-936.

Ebinger, C.K., 2011. Energy and Security in South Asia: Cooperation or Conflict? Brookings Institution Press. URL. http://www.jstor.org/stable/10.7864/j. ctt127x8w.

Elazzaoui, M., 2015. Modeling and control of a wind system based doubly fed induction generator: optimization of the power produced. J. Electr. Electron. 4 (1), 1.

Eremia, M., Shahidehpour, M., 2013. Handbook of Electrical Power System Dynamics: Modeling, Stability, and Control, Vol. 92. John Wiley \& Sons.

Fujimoto, R., Bock, C., Chen, W., Page, E., Panchal, J.H., 2017. Research Challenges in
Modeling and Simulation for Engineering Complex Systems. Springer.

FWEL, 2019. Foundation wind energy limited. URL. http://fwel.com.pk/.

Girsang, I.P., Dhupia, J.S., Muljadi, E., Singh, M., Pao, L.Y., 2014. Gearbox and drivetrain models to study dynamic effects of modern wind turbines. IEEE Trans. Ind. Appl. 50 (6), 3777-3786.

Guo, X., Zhang, X., Du, S., Li, C., Siu, Y.L., Rong, Y., Yang, H., 2020. The impact of onshore wind power projects on ecological corridors and landscape connectivity in shanxi, China. J. Clean. Prod. 254, 120075. https://doi.org/10.1016/ j.jclepro.2020.120075. URL. http://www.sciencedirect.com/science/article/pii/ S0959652620301220.

Hansen, P., Liu, X., Morrison, G.M., 2018. Agent-based modelling and socio-technical energy transitions: a systematic literature review. Energy Res. Soc. Sci 49, $41-52$.

Johnson, G.L., 2001. Wind Turbine Power , Energy , and Torque. Wind Energy Syst, pp. $1-54$.

Ju, L., Tan, Q., Zhao, R., Gu, S., Jiaoyang, Wang, W., 2019. Multi-objective electrothermal coupling scheduling model for a hybrid energy system comprising wind power plant, conventional gas turbine, and regenerative electric boiler, considering uncertainty and demand response. J. Clean. Prod. 237, 117774. https://doi.org/10.1016/j.jclepro.2019.117774. URL. http://www.sciencedirect. com/science/article/pii/S0959652619326344.

Kraan, O., Kramer, G.J., Nikolic, I., 2018. Investment in the future electricity system an agent-based modelling approach. Energy 151, 569-580.

Kremers, E., Durana, J.M.G.D., Barambones, O., Viejo, P., Lewald, N., 2011. Agentbased Simulation of Wind Farm Generation at Multiple Time Scales.

Mahmood, I., Kausar, T., Sarjoughian, H.S., Malik, A.W., Riaz, N., 2019. An integrated modeling, simulation and analysis framework for engineering complex systems. IEEE Access 7, 67497-67514.

Mahmood, I., tul ain, Q., Nasir, H.A., Javed, F., Aguado, J.A., 2020a. A hierarchical multi-resolution agent-based modeling and simulation framework for household electricity demand profile. Simulation 96 (8), 655-678. https://doi.org/ $10.1177 / 0037549720923401$.

Mahmood, I., Arabnejad, H., Suleimenova, D., Sassoon, I., Marshan, A., Serrano, A., Louvieris, P., Anagnostou, A., Taylor, S., Bell, D., et al., 2020b. Facs: a geospatial agent-based simulator for analyzing covid-19 spread and public health measures on local regions. J. Simulat. https://doi.org/10.1080/ 17477778.2020 .1800422$.

Manwell, J.F., McGowan, J.G., Rogers, A.L., 2010. Wind Energy Explained: Theory, Design and Application. John Wiley \& Sons.

Mast, E.H.M., Kuik, G.A.M.V., Bussel, G.J.W.V., 2007. Agent-based Modelling for Scenario Development of Offshore Wind Energy.

Press, I., Shafer, L., Arnold, G.W., Jacobson, D., 2013. Handbook of Electrical Power System Dynamics.

Ringler, P., Keles, D., Fichtner, W., 2016. Agent-based modelling and simulation of smart electricity grids and markets-a literature review. Renew. Sustain. Energy Rev. 57, 205-215.

Sahnoun, M., Baudry, D., Mustafee, N., Louis, A., Smart, P.A., Godsiff, P., Mazari, B., 2015. Modelling and simulation of operation and maintenance strategy for offshore wind farms based on multi-agent system. J. Intell. Manuf. 30.

Saini, S., 2013. Review of doubly fed induction generator used in wind power generation. Int. J. Environ. Sci. Dev. Monit 4, 53-56.

Sarkar, A., Behera, D.K., 2012. Wind turbine blade efficiency and power calculation with electrical analogy. Int. J. Sci. Res. Publ 2 (1), 2250-3153.

Shahid, M., Ullah, K., Imran, K., Mahmood, I., Mahmood, A., 2020. Electricity supply pathways based on renewable resources: a sustainable energy future for Pakistan. J. Clean. Prod. 263, 121511.

Singh, M., Santoso, S., 2011. Dynamic Models for Wind Turbines and Wind Power Plants.

Tapia, A., Tapia, G., Ostolaza, J.X., Saenz, J.R., 2003. Modeling and control of a wind turbine driven doubly fed induction generator. IEEE Trans. Energy Convers. 18 (2), 194-204.

Taylor, S., 2014. Agent-based Modeling and Simulation. Springer.

Teunter, R.H., Syntetos, A.A., Babai, M.Z., 2011. Intermittent demand: linking forecasting to inventory obsolescence. Eur. J. Oper. Res. 214 (3), 606-615.

Valasai, G.D., Uqaili, M.A., Memon, H.R., Samoo, S.R., Mirjat, N.H., Harijan, K., 2017. Overcoming electricity crisis in Pakistan: a review of sustainable electricity options. Renew. Sustain. Energy Rev. 72, 734-745.

Valipour, K., Najafi, R., Bakhshi, M., 2016. Mathematical modeling and simulation of DFIG wind turbine. J. Eng. Appl. Sci. 11 (9), 2072-2078.

Vasirani, M., Kota, R., Cavalcante, R.L.G., Ossowski, S., Jennings, N.R., 2013. An agentbased approach to virtual power plants of wind power generators and electric vehicles. IEEE Transactions on Smart Grid 4 (3), 1314-1322.

Wang, C.S., Chiang, M.H., 2016. A novel dynamic co-simulation analysis for overall closed loop operation control of a large wind turbine. Energies 9 (8).

Zhang, F., 2018. World Bank Group. In the Dark : How Much Do Power Sector Distortions Cost South Asia?, vol. 1. South Asia Development Forum, Washington, D.C., p. 51. URL. http://documents.worldbank.org/curated/en/ 462261544568063923/In-the-Dark-How-Much-Do-Power-Sector-DistortionsCost-South-Asia

Zhang, W., Maleki, A., Rosen, M.A., 2019. A heuristic-based approach for optimizing a small independent solar and wind hybrid power scheme incorporating load forecasting. J. Clean. Prod. 241, 117920. https://doi.org/10.1016/j.jclepro.2019.117920. URL. http://www.sciencedirect.com/science/article/pii/ S0959652619327908. 
Imran Mahmood is currently working as Senior Research Fellow at the Department of Computer Science, Brunel University London. He has served as Assistant Professor at the Department of Computing, School of Electrical Engineering and Computer Science, National University of Sciences and Technology, (Pakistan). Imran earned his Masters and doctoral degrees in Computer Systems at the School of Information and Communication Technology (ICT), KTH-Royal Institute of Technology Sweden in 2007 and 2013 respectively. He is the founding Director of the Center for Research in Modeling and Simulation (CRIMSON). His current research interests are in applied modeling, simulation, analysis and formal verification of complex systems. He is the Principal Investigator of the funded project: 'Simulation Modeling, Analysis and Forecasting of Electricity Generation in Pakistan using System Dynamics Approach'

Mahe Mobeen is a post-graduate student at Department of Electrical Engineering, School of Electrical Engineering and Computer Science, National University of Sciences and Technology (Pakistan). She is serving as a Resident Researcher in Center for Research in Modeling and Simulation (CRIMSON). Her current research interests are in modeling, simulation and analysis of Electricity Generation in Pakistan.

Anis Ur Rahman received the master's degree in parallel and distributed systems from Joseph Fourier University, France, and the Ph.D. degree in computer science from Grenoble University, France, in 2013. He is currently an Assistant Professor with NUSTSEECS, Pakistan. Besides, he has also served as a Research Fellow with the Faculty of Computer Science and Information Technology, University of Malaya, Malaysia. His main research interests include the internet of things, simulation and modeling, computational science and machine learning.

Shahzad Younis received the bachelor's degree from the National University of Sciences and Technology (NUST), Islamabad, Pakistan, in 2002, the master's degree from the University of Engineering and Technology, Taxila, Pakistan, in 2005, and the Ph.D. degree from the University Technology PETRONAS, Perak, Malaysia, in 2009. Before joining NUST, he was the Assistant Manager at a research and development organization named AERO, where he was involved indifferent signal processing and embedded system design applications. He is currently an Assistant Professor with the Department of Electrical Engineering, School of Electrical Engineering and Computer Science, NUST. He has authored or co-authored over 25 papers in domestic and international journals and conferences. His research interests include statistical signal processing, adaptive filters, convex optimization biomedical signal processing, wireless communication modeling, and Digital Signal Processing

Asad Waqar Malik(Senior Member, IEEE) received the Ph.D. degree in computer software engineering from NUST, Pakistan. He is currently an Assistant Professor with the School of Electrical Engineering and Computer Science, NUST. Previously, he worked as a senior lecturer at the University of Malaya, Malaysia. His research interests include parallel and distributed simulation, cloud computing, and large-scale networks. He is the PI on the distributed simulation projects such as CloudNetSim, FogNetSim, and SEECSim.

Muhammad Moazam Fraz is a Tenured Associate Professor at NUST-SEECS, Islamabad, Pakistan. He is currently Rutherford Fellow at The Alan Turing Institute, London; which is UK's National Center for Data Science and AI. His research interests include deep learning, visual data analytics and data mining.

Kafait Ullah is currently working as an Assistant Professor in Energy Economics, Policy and Governance at US-Pakistan Center for Advanced Studies in Energy (USPCAS-E), National University of Science and Technology (NUST). He acquired his MS in Development Economics from the University of Life Science, Norway and PhD in Energy Economics and Policy from the University of Twente, the Netherlands. His major areas of interests include energy sector liberalization, institutional economics of public sector utilities, energy poverty, diffusion of energy innovations, integrated energy planning and economics of renewable energy resources 